\title{
Self-medication and its Consequences during \& after the Coronavirus Disease 2019 (COVID-19) Pandemic: A Global Health Problem
}

\author{
Steward Mudenda ${ }^{1,2 *}$, Bwalya Angel Witika ${ }^{3}$, Mohammad Jaffar Sadiq ${ }^{4}$, Michelo Banda ${ }^{1}$, \\ Ruth Lindizyani Mfune ${ }^{2,5}$, Victor Daka ${ }^{2,5}$, Damaless Kalui ${ }^{1}$, Maureen Nkandu Phiri ${ }^{1}$, Maisa Kasanga ${ }^{6,7}$, \\ Frank Mudenda ${ }^{8}$, Webrod Mufwambi ${ }^{1}$
}

\footnotetext{
${ }^{1}$ University of Zambia, School of Health Sciences, Department of Pharmacy, P.O. Box 50110, Lusaka, ZAMBIA

${ }^{2}$ University of Zambia, School of Veterinary Medicine, Department of Disease Control, P.O Box 32379, Lusaka, ZAMBIA

${ }^{3}$ Department of Pharmacy, DDT College of Medicine, P.O Box 70587, Gaborone, BOTSWANA

${ }^{4}$ Department of Pharmacology, Batterjee Medical College for Science and Technology, Jeddah, SAUDI ARABIA

${ }^{5}$ Copperbelt University, Michael Chilufya Sata School of Medicine, P.O Box 71191, Ndola, ZAMBIA

${ }^{6}$ University Teaching Hospitals, P/Bag RW1X, Lusaka, ZAMBIA

${ }^{7}$ Zhengzhou University, College of Public Health, 100 Kexue Avenue, Zhengzhou, Henan 450001 CHINA

${ }^{8}$ University of Pretoria, Department of Civil Engineering, Pretoria, Hatfield, 0001, SOUTH AFRICA

*Corresponding Author: freshsteward@gmail.com
}

Citation: Mudenda, S., Witika, B. A., Sadiq, M. J., Banda, M., Mfune, R. L., Daka, V., Kalui, D., Phiri, M. N., Kasanga, M., Mudenda, F. and Mufwambi, W. (2020). Self-medication and its Consequences during \& after the Coronavirus Disease 2019 (COVID-19) Pandemic: A Global Health Problem. European Journal of Environment and Public Health, 5(1), em0066. https://doi.org/10.29333/ejeph/9308

\section{ARTICLE INFO}

Received: 2 Sep. 2020

Accepted: 13 Oct. 2020

\begin{abstract}
Coronavirus disease 2019 (COVID-19) is a respiratory tract infection that emerged from China in December 2019 and is caused by severe acute respiratory syndrome coronavirus 2 . Due to the airborne nature of its transmission, COVID-19 spread to the rest of the world rapidly. Thus, the World Health Organization declared COVID-19 a pandemic. This paper evaluated the factors that lead to self-medication in people suffering from respiratory tract infections such as COVID-19, and the consequences of practicing self-medication using antimicrobial agents. Most of the signs and symptoms of COVID-19 are also seen in infections such as malaria, flu, and the common cold. For this reason, and also due to poor healthcare-seeking behaviour, most people tend to self-medicate using medicines that are known to be effective against malaria, common cold, and COVID-19. Among the commonly used medicines in the practice of self-medication include antibacterials, antimalarials, and antivirals. Some vitamins such as vitamin $\mathrm{C}$ boost the immune system enabling it to provide effective defence mechanisms against microbes. However, self-medication may pose consequences such as the emergence of antimicrobial-resistant microorganisms, hypersensitivity reactions as well as dose-dependent toxicities viz dermatoxicity, cardiotoxicity, and hepatoxicity. Infectious diseases caused by antimicrobial-resistant microbes are difficult and, in some instances, impossible to treat thereby leading to increased morbidity and mortality among infected people. Consequently, antimicrobial resistance poses another global public health problem and requires a multisectoral approach to curb. It is our recommendation that all governments ensure that there are adequate medicines and efficient human resources in healthcare facilities as well as sufficient public awareness to prevent people from seeking self-medication.
\end{abstract}

Keywords: Coronavirus disease 2019, COVID-19, self-medication, antimicrobial resistance, antibiotics, antimalarials, antivirals

Coronavirus disease 2019 (COVID-19) is a global public health problem that originated from Wuhan city of Central China's Hubei Province in December 2019 (Guo et al., 2020; Kasanga et al., 2020). COVID-19 is caused by severe acute respiratory syndrome coronavirus 2 (SARS-CoV-12) (Guan et al., 2020; Guo et al., 2020; Mudenda et al., 2020a). COVID-19 spread rapidly from China to the rest of the world and was declared a global pandemic by the World Health Organization
(WHO) on the $11^{\text {th }}$ March 2020 (ECDC, 2020; Mudenda, 2020). COVID-19 is transmitted through the inhalation of droplets, aerosols, fomites, contact routes, and faeces (Li et al., 2020; Wang et al., 2020; WHO, 2020; Zhang et al., 2020). The rapid spread of the disease led to country lockdowns worldwide limiting international movement and, in some cases, restricting trade (Barkur et al., 2020). This could have affected the availability of medicines in healthcare facilities and 
movements, thereby preventing people from visiting healthcare facilities for medical services. This was further compounded by poor compliance to preventive measures such as social distancing, wearing face masks, hand hygiene, as well as lack of laboratory test kits and reagents that have compromised the control of COVID-19 (Zambia Situation Report, 2020). The purpose of this paper was to evaluate the factors that lead to self-medication in people suffering from respiratory tract infections such as COVID-19, and the consequences of self-medication with antimicrobial agents.

Self-medication is the practice of taking medicines, herbs, or home remedies on one's initiative, or on the advice of another person, without consulting healthcare professionals (Bennadi, 2013). The signs and symptoms associated with COVID-19 include a dry cough, headache, fever, flu, fatigue, joint pains, nausea, vomiting, and diarrhoea (Chinese CDC, 2020; Mudenda, 2020). Most of these signs and symptoms also manifest in conditions such as the common cold, flu, whooping cough, and malaria. Due to these similarities in clinical presentations coupled with increased poor healthseeking behaviour, many people have resorted to selfmedicating behaviour (Hussain et al., 2019). Thus, the emergence of COVID-19 has led to an increase in selfmedication practice among different populations including healthcare workers (Onchonga et al., 2020). Poor healthseeking behaviour is influenced by factors such as cultural beliefs, socio-economic factors such as level of education, availability of medicines, absence or lack of qualified healthcare professionals, perceived quality of health services, and accessibility to healthcare facilities (Hussain et al., 2019). Other factors that could contribute to self-medication practices during the COVID-19 pandemic could include reduced hospital visits due to fear of contracting COVID-19 (Wong et al., 2020), the media touting medicines purported to have activity against COVID-19 and internet use for health information (Islam et al., 2020). Rampant COVID-19 related infodemics or rumours have contributed to self-medication because they spread wrong information about possible medicines used in prophylaxis and treatment of COVID-19 (Islam et al., 2020). Racial and social discrimination has been reported to be among the factors that can deter people from accessing healthcare services (Budhwani \& Sun, 2020; Devakumar et al., 2020; Habersaat et al., 2020). These factors play a huge role in promoting self-medication among members of the community thereby deterring them from seeking medical services in health facilities.

There is strong evidence showing that people selfmedicate using antibiotics such as azithromycin (AZM), a macrolide widely used for the treatment of communityacquired pneumonia (CAP) and sexually transmitted infections (STIs) (CDC, 2020; Molento, 2020). Other medicines that are commonly being used for self-medication are antimalarials such as chloroquine (CQ) and hydroxychloroquine (HCQ) that are believed to be effective in the prophylaxis and treatment of COVID-19 (Ministry of Health Zambia, 2020; Molento, 2020). This has consequently led to shortage of hydroxychloroquine because of its overuse and misuse during the COVID-19 era (Mehta et al., 2020). Besides, many reports have shown that people self-medicate using many other antibiotics and antivirals as a way of preventing and treating COVID-19 while staying at home (Ministry of Health Zambia, 2020; Nasir et al., 2020). Antivirals, more specifically, antiretrovirals (ARVs) are among the medicines that people are using to confer prophylaxis from COVID-19. The anthelminthic, ivermectin, is also among the medicines that are misused or abused for self-medication against COVID-19 (Molento, 2020). Vitamins play an important role as immunostimulants, antioxidants, and have a cardinal role in repairing damaged cells and promoting healing (Chambial et al., 2013). Vitamin C (ascorbic acid) is among the most commonly self-medicated vitamin. Vitamin $\mathrm{C}$ boosts the immune system and helps the body to fight foreign bodies effectively (Chambial et al., 2013; Hiedra et al., 2020). Vitamin $\mathrm{C}$ can be sourced from foodstuffs such as oranges, cabbage, red pepper, broccoli, cauliflower, spinach, tomatoes and tomato source, sweet and Irish potatoes (Chambial et al., 2013). Additionally, self-medication with supplementary minerals such as zinc ( $\mathrm{Zn})$ is also being used in the prevention and treatment of COVID-19 symptoms due to its ability to enhance innate and adaptive immunity in the course of a viral infection (Hunter et al., 2020; Kumar et al., 2020; Rahman et al., 2020). Despite the beneficial effects of zinc in immune response, long-term high-dose consumption may result in unwanted effects (Rahman et al., 2020). Moreover, people still need to consult their healthcare professionals on the use of vitamins even in pandemics such as COVID-19.

Due to fear of contracting COVID-19 in the hospital environment and ease of access to medicines, many people have stopped visiting healthcare facilities for their medical services (Wong et al., 2020). Unfortunately, this has led to many deaths occurring in settings outside of healthcare facilities (Ministry of Health Zambia, 2020). Self-medication may pose consequences such as the escalation of antimicrobial resistance (AMR) and toxicity (Ministry of Health Zambia, 2020; Phiri et al., 2020). Antimicrobial resistance (AMR) may occur as a result of self-medication, misuse, and abuse of antimicrobials (Kalonga et al., 2020; Mudenda et al., 2019; Zulu et al., 2020). The impact of AMR is prolonged hospital stay for patients, increased resource utilisation, economic and clinical burden, and increased morbidity and mortality rates (Friedman et al., 2016; Mudenda et al., 2019, 2020b; Zulu et al., 2020). COVID-19 is likely going to escalate antimicrobial resistance and its consequences (Hsu, 2020). Therefore, the rational and appropriate use of antimicrobial agents must be strictly observed to avoid the consequences of AMR (Hangoma et al., 2020; Lee et al., 2013; Saleem et al., 2018). Antimicrobial stewardship should not be ignored during the COVID-19 era (Huttner et al., 2020). Toxicity has been reported in some cases of self-medication with antimalarial agents and can lead to damage to vital organs such as the kidneys, liver, and the heart (Ministry of Health Zambia, 2020). Therefore, people must always seek medical help should they feel sick. Currently, there are no approved medicines and vaccines against COVID-19 (Ali \& Alharbi, 2020; Sanders et al., 2020). In some cases, supportive management of COVID-19 may include the use of Allopathic medicines such as oxygen therapy, intravenous fluid infusion, Unani (plant-based) medicines such as Allium sativum and Allium cepa, Homeopathy using Arsenic Album30, and immune boosters such as vitamin C (Ali \& Alharbi, 
2020). However, many potential medicines and vaccines are still undergoing clinical trials (Sanders et al., 2020).

In conclusion, self-medication during COVID-19 with prescription-only medicines may result in increased morbidity and mortality. Self-medication with some vitamins can play a role in boosting the immune system but there are no evidencebased studies that report the use of vitamins as a cure of COVID-19. We, therefore, encourage everyone to seek medical help should they experience COVID-19 related signs and symptoms.

The authors would, therefore, make the following recommendations;

(i) People should develop good healthcare-seeking behaviour. This can only be done by effective community sensitization and engagement programmes that can be facilitated by the Ministries or departments responsible for health.

(ii) People should desist from practicing selfmedication using antibiotics, antivirals, and antimalarials, as well as other prescription-only medicines.

(iii) Comprehensive health education must be carried out to promote awareness on the possible risks of selfmedication.

(iv) Governments in conjunction with Ministries and departments responsible for health must ensure that healthcare facilities are adequately equipped with medicines to avoid stock-outs. Lack of medicines in hospitals is a major factor that may force people to seek medicines elsewhere and practice self-medication.

(v) Governments must employ adequately trained healthcare workers who are, effective, and efficient in their provision of healthcare services.

(vi) Governments must strengthen the enforcement of COVID-19 mitigation measures and support individuals with resources to enable them adhere to COVID-19 prevention guidelines such as working from home.

(vii) People must be wearing face masks, practice adequate handwashing or use alcohol-based hand sanitizers, social distancing, and stay at home whenever necessary.

(viii) Individuals who suspect to have symptoms of COVID-19 or have had contact with positive COVID-19 symptomatic patients should seek medical attention based on the local protocol of accessing medical care in suspected cases of COVID-19.

(ix) Individuals must seek medical attention when symptoms of COVID-19 are observed to avoid disease progression and complication.

(x) The media must continue playing important roles in reducing COVID-19 related infodemics and promoting adherence to preventive measures.

\section{ACKNOWLEDGEMENTS}

We are grateful to the University of Zambia Library for providing access to the majority of the articles that we used in this publication.

\section{REFERENCES}

Ali, I. and Alharbi, O. M. L. (2020). COVID-19: disease, management, treatment, and social impact. Sci. Total Environ, 728, 138861. https://doi.org/10.1016/j.scitotenv. 2020.138861

Barkur, G., Vibha and Kamath, G. B. (2020). Sentiment analysis of nationwide lockdown due to COVID 19 outbreak: Evidence from India. Asian journal of psychiatry, 51, 102089. https://doi.org/10.1016/j.ajp.2020.102089

Bennadi, D. (2013). Self-medication: A current challenge. J Basic Clin Pharm, 5(1), 19-23. https://doi.org/10.4103/ 0976-0105.128253

Budhwani, H. and Sun, R. (2020). Creating COVID-19 stigma by referencing the novel coronavirus as the "Chinese virus" on Twitter: quantitative analysis of social media data. J. Med. Internet Res, 22, e19301. https://doi.org/ 10.2196/19301

Centres for Disease Control and Prevention. (2020). Azithromycin shortage. [cited 2020 15th September]; Available at: https:/www.cdc.gov/std/treatment/ drugnotices/azithromycin-2020.htm

Chambial, S., Dwivedi, S., Shukla, K. K., John, P. J., et al. (2013). Vitamin $\mathrm{C}$ in disease prevention and cure: an overview. Indian $J$ Clin Biochem, 28, 314-328. https://doi.org/10.1007/s12291-013-0375-3

Chinese Center for Disease Control and Prevention. (2020). Epidemic update and risk assessment of 2019 Novel Coronavirus 2020 [updated 29 January 2020; cited 202029 July]. Available at: http://www.chinacdc.cn/yyrdgz/202001 /P020200128523354919292.pdf

Devakumar, D., Shannon, G., Bhopal, S. S. and Abubakar, I. (2020). Racism and discrimination in COVID-19 responses. Lancet, 395, 1194. https://doi.org/10.1016/S01406736(20)30792-3

European Centre for Disease Prevention and Control (ECDC). (2020). Novel coronavirus disease 2019 (COVID-19) pandemic: increased transmission in the EU/EEA and the UK - sixth update - 12 March 2020. Stockholm: ECDC. Available at: https://www.ecdc.europa.eu/sites/default/files/ documents/RRA-sixth-update-Outbreak-of-novelcoronavirus-disease-2019-COVID-19.pdf

Friedman, N. D., Temkin, E. \& Carmeli Y. (2016). The negative impact of antibiotic resistance. Clin Microbiol Infect, 22, 416-422. https://doi.org/10.1016/j.cmi.2015.12.002

Guan, W. J., Ni, Z. Y., Hu, Y., Liang, W. H., Ou, C. Q., He, J. X., et al. (2020). Clinical characteristics of coronavirus disease 2019 in China. $N$ Engl J Med, 382, 1708-1720. https://doi.org/10.1056/NEJMoa2002032

Guo, Y., Cao, Q., Hong, Z., et al. (2020). The origin, transmission, and clinical therapies on coronavirus disease 2019 (COVID-19) outbreak - an update on the status. Military Med Res, 7, 11. https://doi.org/10.1186/s40779020-00240-0 
Habersaat, K.B., Betsch, C., Danchin, M., et al. (2020). Ten considerations for effectively managing the COVID-19 transition. Nat Hum Behav, 4, 677-687. https://doi.org/10.1038/s41562-020-0906-X

Hangoma, J. M., Mudenda, S., Mwenechanya, M. M. and Kalungia, A. C. (2020). Community pharmacists' knowledge and preparedness to participate in the fight against Coronavirus disease 2019 (COVID-19) in Zambia. medRxiv. https://doi.org/10.1101/2020.09.01.20185694

Hiedra, R., Lo, B. K., Elbashabsheh, M., Gul, F., Wright, M. R, Albano, J., Azmaiparashvili, Z. and Aponte, G. P. (2020). The use of IV vitamin C for patients with COVID-19: a case series. Expert Review of Anti-infective Therapy, Published online: 1 August 2020. https://doi.org/10.1080/ 14787210.2020.1794819

Hsu, J. (2020). How COVID-19 is accelerating the threat of antimicrobial resistance. BMJ, 369, m1983. https://doi.org/10.1136/bmj.m1983

Hunter, J., Arentz, S., Goldenberg, J., Yang, G., Beardsley, J. and Mertz, D. (2020). Rapid review protocol: zinc for the prevention or treatment of COVID-19 and other coronavirus-related respiratory tract infections. Integrative medicine research, 100457. https://doi.org/10.1016/ j.imr.2020.100457

Hussain, R., Rashidian, A., Hafeez, A. and Mirzaee, N. (2019). Factors Influencing Healthcare Seeking Behaviour At Primary Healthcare Level, In Pakistan. Journal of Ayub Medical College, Abbottabad: JAMC, 31, 201-6.

Huttner, B. D., Catho, G., Pano-Pardo, J. R., Pulcini, C. and Schouten, J. (2020). COVID-19: dont neglect antimicrobial stewardship principles! Clin Microbiol Infect, 26(7), 808810). https://doi.org/10.1016/j.cmi.2020.04.024

Islam, M. S., Sarkar, T., Khan, S. H., Mostofa Kamal, A. H., Hasan, S. M. M., Kabir, A., Yeasmin, D., Islam, M. A., Amin Chowdhury, K. I., Anwar, K. S., Chughtai, A. A. and Seale, H. (2020). COVID-19-Related Infodemic and Its Impact on Public Health: A Global Social Media Analysis. The American Journal of Tropical Medicine and Hygiene, 103(4), 1621-1629. https://doi.org/10.4269/ajtmh.20-0812

Kalonga, J., Hangoma, J., Banda, M., Munkombwe, D. and Mudenda, S. (2020). Antibiotic Prescribing Patterns in Paediatric Patients at Levy Mwanawasa University Teaching Hospital in Lusaka, Zambia. International Journal of Pharmaceutics \& Pharmacology, 4(1), 1-9. https://doi.org/10.31531/2581-3080.1000138

Kasanga, M., Mudenda, S., Gondwe, T., Chileshe, M., Solochi, B. and $\mathrm{Wu}, \mathrm{J}$. (2020). Impact of COVID-19 on blood donation and transfusion services at Lusaka provincial blood transfusion centre, Zambia. Pan African Medical Journal, 35(2), 74. https://doi.org/10.11604/pamj.supp. 2020.35.2.23975

Kumar, A., Kubota, Y., Chernov, M., and Kasuya, H. (2020). Potential role of zinc supplementation in prophylaxis and treatment of COVID-19. Med Hypotheses, 144, 109848. https://doi.org/10.1016/j.mehy.2020.109848
Lee, C. R., Cho, I. H., Jeong, B. C., and Lee, S. H. (2013). Strategies to minimize antibiotic resistance. International journal of environmental research and public health, 10(9), 4274-4305. https://doi.org/10.3390/ijerph10094274

Li, Q., Guan, X., Wu, P., et al. (2020). Early transmission dynamics in Wuhan, China, of novel coronavirus-infected pneumonia. $N$ Engl $J$ Med, 382, 1199-1207. https://doi.org/10.1056/NEJMoa2001316

Mehta, B., Salmon, J., Ibrahim, S., editors. (2020). Potential Shortages of Hydroxychloroquine for Patients with Lupus during the Coronavirus Disease 2019 Pandemic. JAMA Health Forum: American Medical Association. Published online 10 April 2020. https://doi.org/10.1001/ jamahealthforum.2020.0438

Ministry of Health, Zambia. (2020). MoH warns against selfmedicating, as COVID-19 deaths hit 200. News Diggers! Available at: https://diggers.news/local/2020/08/07/mohwarns-against-self-medicating-as-covid-19-deaths-hit200/

Molento, M. B. (2020). COVID-19 and the rush for selfmedication and self-dosing with Ivermectin: A word of caution. One Health, 10, 100148. https://doi.org/10.1016/ j.onehlt.2020.100148

Mudenda, S. (2020). Coronavirus Disease (COVID-19): A Global Health Problem. Int J Pharm Pharmacol, 4, 141. https://doi.org/10.31531/2581-3080.1000141

Mudenda, S., Bangara, F. F, Sitali, J. and Banda, M. (2019). Knowledge, attitude, and practices on antibiotic resistance among Pharmacists at the University Teaching hospitals in Lusaka, Zambia. Journal of Harmonized Research in Pharmacy, 8, 12-24. https://doi.org/10.30876/JOHR.8.2. 2019.12-24

Mudenda, S., Hankombo, M., Saleem, Z., Sadiq, M. J., Banda, M., Munkombwe, D., Mwila, C., et al. (2020b). Knowledge, Attitude, and Practices of Community Pharmacists on Antibiotic Resistance and Antimicrobial Stewardship in Lusaka, Zambia. medRxiv. https://doi.org/10.1101/ 2020.08.27.20181826

Mudenda, S., Zulu, A., Phiri, M. N., Ngazimbi, M., Mufwambi, W., Kasanga, M. and Banda, M. (2020a). Impact of Coronavirus Disease 2019 (COVID-19) on College and University Students: A Global Health and Education Problem. Aquademia, 4(2), ep20026. https://doi.org/ 10.29333/aquademia/8494

Nasir, M., Talha, K. A., Chowdhury, A. S., Zahan, T. and Perveen, R. A. (2020). Prevalence, Pattern and Impact of Self Medication of Anti-infective Agents during COVID-19 Outbreak in Dhaka City. https://doi.org/10.21203/rs.3.rs57011/v1

Onchonga, D., Omwoyo, J. and Nyamamba, D. (2020). Assessing the Prevalence of Self-Medication among Healthcare Workers before and during the 2019 SARS-CoV2 (COVID-19) Pandemic in Kenya. Saudi Pharmaceutical Journal, 28(10), 1149-1154. https://doi.org/10.1016/j.jsps. 2020.08.003 
Phiri, M. N., Banda, M., Mudenda, S., Ngazimbi M, Hangoma J, Mufwambi W., et al. (2020). Coronavirus Disease 2019 (COVID-19): The Role of Pharmacists in the Fight against COVID-19 Pandemic. Int J Pharm Pharmacol, 4, 143. https://doi.org/10.31531/2581-3080.1000143

Rahman, M. T. and Idid, S. Z. (2020). Can Zn Be a Critical Element in COVID-19 Treatment? Biol Trace Elem Res, 1-9. https://doi.org/10.1007/s12011-020-02194-9

Saleem, Z., Hassali, M. A. and Hashmi, F. K. (2018). Pakistan's national action plan for antimicrobial resistance: translating ideas into reality. Lancet Infect Dis, 18(10), 1066-1067. https://doi.org/10.1016/S1473-3099(18)305164

Sanders, J. M., Monogue, M. L., Jodlowski, T. Z. and Cutrell J. B. (2020). Pharmacologic Treatments for Coronavirus Disease 2019 (COVID-19): A Review. JAMA, 323, 18241836. https://doi.org/10.1001/jama.2020.6019

Wang, M., Jiang, A., Gong, L., Luo, L., Guo, W., Li, C., Zheng, J., Li, C., Yang, B., Zeng, J. and Chen, Y. (2020). Temperature significant change COVID-19 Transmission in 429 cities. MedRxiv. https://doi.org/10.1101/2020.02. 22.20025791
Wong, L., Hawkins, J., Langness, S., Murrell, K. L., Iris, P. and Sammann, A. (2020). Where are all the patients? Addressing covid-19 fear to encourage sick patients to seek emergency care. NEJM Catal Innov Care Deliv. https://catalyst.nejm.org/doi/full/10.1056/CAT.20.0193

World Health Organization (WHO). (2020). Modes of Transmission of Virus Causing COVID-19: Implications for IPC Precaution Recommendations: Scientific Brief, 27 March 2020. Available at: https://apps.who.int/iris/handle/10665/ 331601

Zambia Situation Report. (2020). Reliefweb. Available at: https://reliefweb.int/report/zambia/zambia-situationreport-20-august-2020 (Accessed: 22 August 2020).

Zhang, J., Wang, S. and Xue, Y. (2020). Fecal specimen diagnosis 2019 novel coronavirus-infected pneumonia. $J$. Med. Virol, 92, 680-682. https://doi.org/10.1002/jmv.25742

Zulu, A., Matafwali, S. K., Banda, M. and Mudenda, S. (2020). Assessment of knowledge, attitude and practices on antibiotic resistance among undergraduate medical students in the school of medicine at the University of Zambia. Int $J$ Basic Clin Pharmacol, 9, 263-270. https://doi.org/10.18203/2319-2003.ijbcp20200174 